This article was downloaded by: [Gonçalves, Miguel]

On: 19 May 2011

Access details: Access Details: [subscription number 937788453]

Publisher Routledge

Informa Ltd Registered in England and Wales Registered Number: 1072954 Registered office: Mortimer House, 3741 Mortimer Street, London W1T 3JH, UK

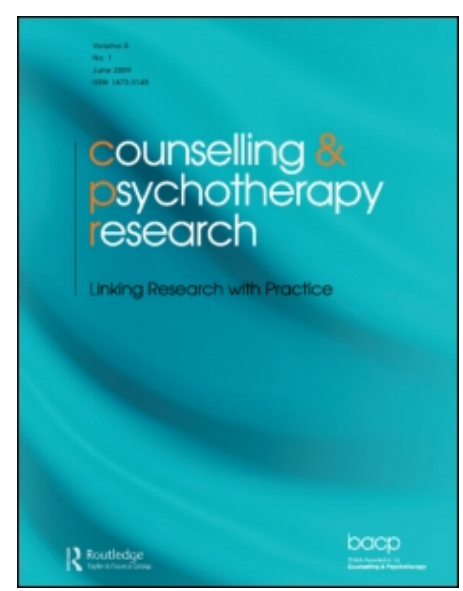

\title{
Counselling and Psychotherapy Research
}

Publication details, including instructions for authors and subscription information:

http://www.informaworld.com/smpp/title $\sim$ content=t713734893

\section{Innovative moments and poor outcome in narrative therapy}

Anita Santos ; Miguel M. Gonçalves ${ }^{\mathrm{b}}$; Marlene Matos

${ }^{a}$ ISMAI - Instituto Superior da Maia, Maia, Portugal ${ }^{b}$ Department of Psychology, University of Minho,

Braga, Portugal

First published on: 22 April 2010

To cite this Article Santos, Anita , Gonçalves, Miguel M. and Matos, Marlene(2011) 'Innovative moments and poor outcome in narrative therapy', Counselling and Psychotherapy Research, 11: 2, 129 - 139, First published on: 22 April 2010 (iFirst)

To link to this Article: DOI: $10.1080 / 14733140903398153$

URL: http://dx.doi.org/10.1080/14733140903398153

\section{PLEASE SCROLL DOWN FOR ARTICLE}

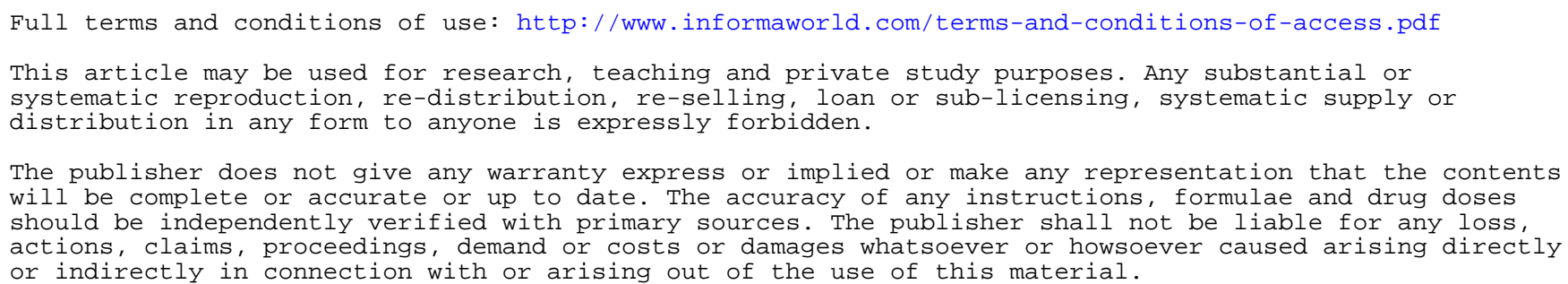




\title{
Innovative moments and poor outcome in narrative therapy
}

\author{
ANITA SANTOS ${ }^{1}$, MIGUEL M. GONÇALVES ${ }^{2 \star}$, \& MARLENE MATOS ${ }^{2}$ \\ ${ }^{1}$ ISMAI - Instituto Superior da Maia, Maia, Portugal $\mathcal{E}^{2}$ Department of Psychology, University of Minho, Braga, Portugal
}

\begin{abstract}
Aims: To analyse a poor outcome case of narrative therapy with a woman victim of intimate violence. Method: The Innovative Moments Coding System: version 1 was applied to all sessions to track the innovative moments (i-moments) in the therapeutic process. I-moments are the narrative details that occur in psychotherapeutic conversations that are outside the influence of the problematic narrative. This research aims to describe the processes involved in the stability of meanings in psychotherapy through a dialogical approach to meaning making. Findings: Contrarily to what usually occurs in good outcome cases, re-conceptualization i-moments are absent. Moreover, two specific types of i-moments emerged with higher duration: reflection and protest. Qualitative analysis showed that the potential meanings of these i-moments were surpassed by a return to the problematic narrative. Conclusion: The therapeutic stability seems to be maintained by a systematic return to the problematic narrative after the emergence of novelties. This process was referred from a dialogical perspective as a mutual in-feeding of voices, one that emerges in the i-moment and another one that supports the problematic narrative, which is maintained by an oscillation between these two types of voices during therapy.
\end{abstract}

Keywords: i-moments; narrative therapy; poor outcome case; dialogical processes; mutual in-feeding

\section{Introduction}

According to White and Epston (1990) '.... alternative stories can be generated or regenerated through a performance of meaning around unique outcomes' (p. 32). Unique outcomes can be episodes, thoughts, feelings, and so on, that are different from the way a client constructs his or her own experiences, and are usually trivialised or neglected in people's lives. In narrative therapy, unique outcomes should be identified and amplified so that clients can 'engage in performances of new meaning in relation to them' (White \& Epston, 1990, p. 41).

Unique outcomes may be conceived as narrative exceptions, while the dominant narrative (e.g. depression, fear) of people's lives may be conceived as the rule. The dominant narrative, or narratives, entails the meanings that clients bring to psychotherapy about their specific problem or symptoms, providing a plot for people's lives. White (2007) refers to these dominant narratives that clients bring to therapy as 'problem-saturated accounts of their lives' (p. 39) that 'have shaped their negative conclusions about their life and their identity' (p. 27).

\section{Problematic narratives}

The dominant narratives can be better understood (from the notion of macro organiser of self's meaning system ${ }^{1}$; Josephs \& Valsiner, 1998) as if composed of a set of laws that organise the person's experiences and that guarantee stability and expectedness in the meaning making efforts. They tend to be resistant to change and to restrain the generation of new meanings, or even the modification of present ones. In sum, they seem to maintain the prevailing meanings system, being composed of a dominant voice that suppresses other possible voices and makes 'the negotiation of meaning a very difficult task' (Gonçalves \& Guilfoyle, 2006, p. 253). They usually impose restrictive conditions on people's lives, as they only allow a certain discourse (e.g. about being a woman), promote certain ways of acting and thinking (e.g. being submissive, being

${ }^{\star}$ Corresponding author. Email: mgoncalves@psi.uminho.pt

ISSN 1473-3145 print/1746-1405 online (C) 2011 British Association for Counselling and Psychotherapy DOI: $10.1080 / 14733140903398153$ 
what a 'good wife' is supposed to be), and deny other possible experiences (e.g. expressing her needs).

\section{Innovative moments}

Unique outcomes, or innovative moments (as we prefer to call them ${ }^{2}$ ) occur often in psychotherapy (as in life), and contribute to the process of self narrative change, as the expansion of these exceptions allows people to construct new rules for living.

In several previous studies with different clients (e.g. suffering from depression, victims of intimate violence), and diverse therapeutic models (narrative, emotion-focused therapy, constructivist approach focused on implicative dilemmas), five different types of innovative moments (or i-moments) were systematically found (Gonçalves, Mendes, Ribeiro, Angus \& Greenberg, 2009; Matos, 2006; Matos, Santos, Gonçalves, \& Martins, 2009; Ribeiro, Gonçalves, \& Ribeiro, 2009; Santos, Gonçalves, Matos, \& Salvatore, 2009): (1) action, (2) reflection, (3) protest, (4) reconceptualization and (5) performing change (see Gonçalves, Ribeiro, Matos, Santos, \& Mendes, 2009). Some examples will be offered to illustrate these different types. In these illustrations we consider as a core rule the problematic narrative of putting other's needs always first and neglecting one's own.

1. Action i-moments refer to specific actions that are not predicted by the dominant narrative. Client: 'Yesterday I went out, instead of going to my mother's house as I used to do'.

2. Reflection i-moments are all the moments in which the person thinks differently to what one might expect from the problematic story, or when one understands something new, that contradicts or does not support the dominant narrative.

Client: 'I've been wondering why I can't express my feelings, why am I not heard in my family. Why should the needs of others always come first?'.

3. Protest i-moments reflect an opposition towards the dominant narrative and its consequences. They can be an action (like in action i-moments) or a thought (like in reflection i-moments), but they are more than mere actions or thoughts, due to their proactive positioning, involving not only resistance but also a re-appreciation of the client's position in relation to the problem.

Client: 'I will not be ignored anymore! I have my needs and I won't accept that they don't count for anything! If I want to respect myself as a person, I need to change this; I need to have the courage to do it'.

4. Re-conceptualization i-moments are more complex than the previous ones. These i-moments involve two components: the contrast between the past self (dominant narrative) and the present self, and the description of the processes that allowed the transformation from the past to the present. Thus, the client not only understands something new, but he or she can also establish a distinction from a previous condition.

Client: 'I learned since I was young to ignore what I want and focus on others' wishes. But now I found that this was a way of treating me as a non-person, making me feel a kind of emptiness that was difficult to live with. Reflecting about my life, and discovering how this way of dealing with others and myself made sense to me in the past, but not anymore, I decided to assert my wishes and this transformed my relationships and also the way I feel inside ...'.

5. Performing change are i-moments in which new projects, activities or experiences that were impossible before, given the constraints of the dominant narrative, start taking place.

Client: 'Now I'm planning to go to night school, I'm ready to go on with my life. My husband is a grown up adult, he can manage his dinner, and I don't have to worry about him'.

I-moments model of change and meaning transformation in narrative therapy

These i-moments were studied in a narrative psychotherapy sample in a previous study (Matos et al., 2009), with 10 women victims of intimate violence. Comparing i-moments in the good and the poor therapeutic outcome group it was concluded that, although they emerged in both groups, the time clients spent elaborating them (duration index), and the types that emerged in each group were different. In sum, i-moments showed a significantly higher duration in the good outcome group, and two i-moments significantly differentiated both groups: re-conceptualization and performing change. Thus, the poor outcome group was characterised by the emergence of mainly action, reflection, and protest i-moments throughout the process. Curiously, these i-moments also characterised early sessions of successful therapy. So, an important question was how 
action, reflection, and protest i-moments in early phases developed differently towards therapeutic success or failure.

\section{Meaning stability in psychotherapy and dialogicality}

From the perspective of positioning theory (Davies \& Harré, 1990), Winslade (2005) suggests that narrative therapy aims are 'to help people disidentify with stories that are proving problematic in their lives and to re-position themselves in alternative narrative trajectories that are more satisfying' (p. 356). So, i-moments are seen as opportunities for clients to position themselves in a discursive stand that is alternative to the 'dominant discourse', or narrative. This interchange between therapist and client entails the creation of a dialogical relation, in which therapist invites the client to position himself or herself differently than usually.

Our main argument is that the emergence of action, reflection, and protest i-moments, when they interact with re-conceptualization, seemed to contribute to a re-positioning of clients in successful therapy, allowing a meaning transformation in therapeutic narratives (Matos et al., 2009).

Gonçalves, Matos, and Santos (2009) suggested that this process may occur for three main reasons. Re-conceptualization has in itself a narrative structure (integrating the previous self and the new self) that facilitated the organisation of other $\mathrm{i}$-moments into a pattern. A virtuous cycle of innovation elaboration and confirmation takes place as the clients recognised themselves as different from the past, which lead them to act, think and feel congruently with this new identity, which further validated the new narrative, and so forth.

The second reason is that by narrating these i-moments, the clients positioned themselves as authors of their own narratives (Sarbin, 1986), and not only as actors, given the access they have to the processes of change.

Finally, without re-conceptualization, the i-moments of action, reflection and protest could have the paradoxical effect of supporting the dominant narrative. Let's examine this third hypothesis in more detail.

We hypothesised that these i-moments could operate as mere oppositions to the problematic narrative, making the problem present even in its absence (e.g. 'I don't want to be depressed anymore'). So, the client oscillates between the elaboration of those i-moments (that temporarily frees the person from the problematic meanings), and the return to the dominant narrative. This seemed to be possible given the lack of further elaboration outside the semiotic domain of the problem that these i-moments sometimes represented, since they could be constructed by the client as a mere negation of the problem's meanings. In this sense, innovation emerged in contrast to the dominant narrative, but did not develop into a new narrative of the self.

Valsiner (2002) described a similar process, called mutual in-feeding, from a dialogical perspective, in which two opposite voices ${ }^{3}$ keep feeding each other, dominating the self narratives alternatively. For instance, the person oscillates between the positions 'I can't free myself from my fears' and 'one day I will enjoy real freedom' (see Figure 1).

From a dialogical point of view, the client performed a cyclical movement between a voice (i-moments) and a counter-voice (problematic narrative) that did not allow the development of the system of meanings throughout therapy. This led to an irresolvable dilemma and made change difficult to achieve. In the case study presented below, this oscillatory process will be further elaborated from a dialogical perspective.

Josephs and colleagues (Josephs \& Valsiner, 1998; Josephs, Valsiner \& Surgan, 1999) conceptualized the meaning transformation from a dialogical perspective. So, meaning-making processes in psychotherapy entail the regulation of dialogical relations between different meanings (Josephs \& Valsiner, 1998; Josephs et al., 1999). Within the scope of this paper, the main meanings that we will analyse are expressed by the problematic narrative and the i-moments. The dialogical relations between these two meanings could

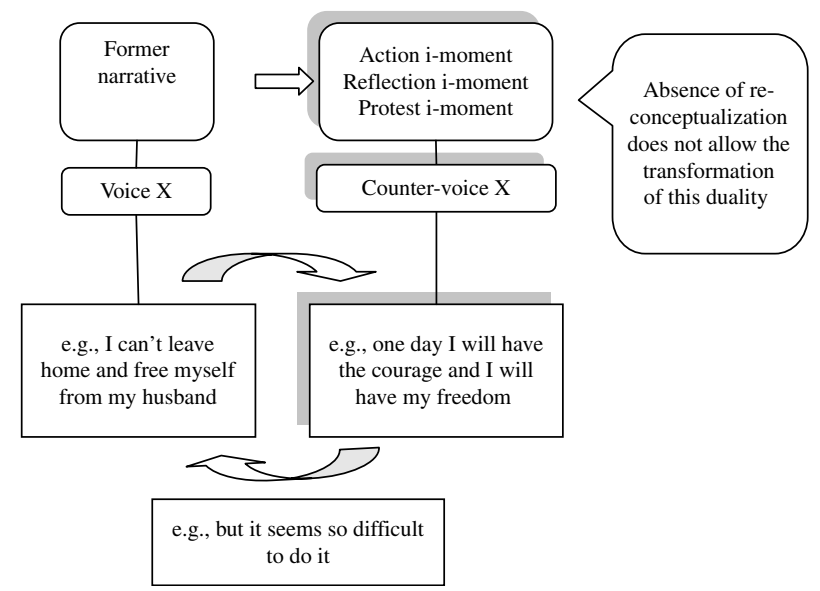

Figure 1. Mutual in-feeding in action, reflection and protest i-moments. Adapted from Gonçalves et al. (2009). 
originate a constructive elaboration of i-moments, leading to an escalation of i-moments and eventually to the consolidation of a new self-narrative. For instance, an i-moment of reflection about the condition of the victim can develop to an i-moment of protest, characterised by self empowerment, as the nature of the first one can be changed and develop into a new one. In therapeutic conversation, if the client chooses to elaborate on new meanings, either by his or her intention or by the therapist's invitation, it is most likely to lead to the development of new meanings. Alternatively, dialogical relations may also prevent new meanings from emerging. We will analyse in the case study situations in which the emergence of imoments, instead of allowing the development of a new self-narrative, leads to a strengthening of the problematic self-narrative. A dialogical interpretation of i-moments' emergence and their relation with the problematic narrative is, from our perspective, an important resource to further understanding the mutual in-feeding (Valsiner, 2002) process in psychotherapy.

\section{Method}

Case study research has been argued to be particularly relevant in psychotherapeutic process research (e.g. Gedo, 1999; Hilliard, 1993; Kazdin, 1981; Kiesler, 1981; Molenaar \& Valsiner, 2005; Morgan \& Morgan, 2001; Yin, 2005). Stiles (2003) suggested 'case studies, as well as statistical hypothesistesting research, can permeate scientific theory and contribute to quality control' (p. 7). A case study methodology, therefore, enables an uncovering of a large number of observations of a specific individual that will contribute to improving or refining theoretical assumptions (Stiles, 2003, 2007). This method was adopted in order to explore which processes can explain mutual in-feeding and meaning stability in a poor outcome clinical case.

\section{Client}

Maria was a 47-year-old retired industrial worker, married for 20 years. She had two sons, one was 16 and the other was 10 years old. Her husband, David, who was physically disabled, had been sexually and psychologically violent toward her since the first year of marriage. Maria was recommended for therapy by an institution for crime victims. In the beginning, she had severe symptoms of depression (e.g. sadness, hopelessness, social withdrawal, isolation). This level of distress was also present in the rating of GSI (Global Severity Index, from the Brief Symptom Inventory; Derogatis, 1982; Portuguese version adapted by Canavarro, 1999) at session one, which was of 2.66 (3 $S D$ above the cutoff point for the Portuguese population without complaints).

Maria was from a very poor family. Her mother died when she was six years old and she had a bad relationship with her father, who was also physically violent toward her during her childhood. Her husband's condition had been an obstacle towards her wishes to leave the relationship, because she pitied him. This resulted in being submissive to her husband and his family. She also had relational problems with her oldest son, as she blamed herself for not being a 'good mother'. Her intent was to leave home with her youngest child to a temporary crime victims' shelter. Her main obstacles were lack of financial independence and the impossibility of taking her oldest son with her.

The meanings that Maria conceived for her life seemed to have been organised and constrained by the cultural and social discourses about women's roles (e.g. submissive, powerless), and the power of men inside the family (Matos \& Gonçalves, 2002). As social discourses available to the victims can be a source of either oppression, or of freedom (Holland, 1997, quoted in Machado \& Matos, 2001), the therapeutic encounter should be, in this sense, a way to rehearse new social discourses and to co-construct new meanings.

Maria's case was selected from a sample of female victims of intimate violence gathered in a previous study (Matos et al., 2009). She underwent individual narrative therapy (White \& Epston, 1990) in a Portuguese university clinic.

This case evolved through 15 sessions, initially four weekly sessions and then twice a month, plus one follow-up (after six months) - sessions 8 and 9 were not rated due to technical problems with video recording procedures. Maria's case was included in the poor outcome group due to an evolution throughout the therapeutic process that maintained psychological distress conditions assessed by the GSI (initial GSI 2.66; final GSI $=0.62$; follow-up GSI $=1.64$ ) and also because there was no change in the level of intimate violence. This case was selected for the study as it was the poor outcome case that showed the highest value for GSI at the follow-up session of the sample. At the same time, this case also presented the lowest values for i-moments' duration. 
The female therapist who attended the case had a master's degree in psychology when the research was developed, and five years of experience in psychotherapy with battered women. Psychotherapy was supervised regarding adherence of the therapist to narrative therapy.

\section{Ethical procedures}

The university clinic approved the study and reviewed and approved the ethical conditions for this research. Maria was informed of the research objectives, generally described as how to understand how psychotherapy helps victims of partner violence. She signed a written consent, where she complied with the videotaping procedures and the use of the data in supervision sessions and in research reports. Treatment was provided with no charge. All the personal details and information that could identify the client were masked or removed from this paper. This case was discussed among coders and researchers only for research purposes.

The Innovative Moments Coding System and coding procedures

The Innovative Moments Coding System: version 1 (IMCS; Gonçalves et al., 2006) was used to analyse processes of change throughout psychotherapy (see Table I.)

The first procedure of IMCS (Gonçalves et al., 2006 ) is to get acquainted with the clinical case, discussing the judges' views on participants' problematic meanings in different contexts (e.g. intrapersonal, interpersonal problems, work, and family). After this consensual definition of what the problematic narrative is, i-moments can be identified, as well as their type and duration (the percentage of time occupied by each i-moment in the session). This case was coded by two trained judges; the reliability index of $86 \%$ of agreement and the Cohen's kappa of .89 (for reliability and full coding procedures see Gonçalves, Ribeiro, et al., 2009).

\section{Findings}

\section{I-moments emergence and duration}

Results from Maria's case showed that i-moments were scarcely elaborated on as the process progressed (see Santos et al., 2009, for a comparison with a good outcome case).
Maria's case findings showed that reflection and protest i-moments were present throughout the process and tended to increase. So, their emergence and evolution will be analysed further on. Action, re-conceptualization, and performing change i-moments will not be considered in the analysis since they were almost absent (see Figure 2).

\section{I-moments emergence and the problematic narrative}

In the narrative therapy, a problem formulation was co-constructed within the therapeutic conversation between Maria and her therapist. As she had been the victim of intimate violence for 20 years, she presented mainly depressive symptoms, lack of entitlement, helplessness, and hopelessness. These negative effects and symptoms of the abusive relationship presented the problem, which was externalised and called the 'wave', following a practice of narrative therapy that invites clients to address the problem as an external 'entity' (White \& Epston, 1990; White, 2007). The next excerpt is from the first session of Maria's case, when client and therapist were elaborating on the 'wave'

\section{First session}

Client: (...) and when my husband started to say all those things, it all came down on me ... it looked like a giant wave, when there are hurricanes or earth quakes, that are extremely high, and that wave came and drew me ...

Therapist: Is this a wave of 'I'm not worthy'? Client: Of I'm not worthy ...

(...)

Therapist: If this wave controls your life forever what would its goal be? What does the wave want for you in your life?

Client: Everything that is negative ... Everything that is negative, that's what I can say ...

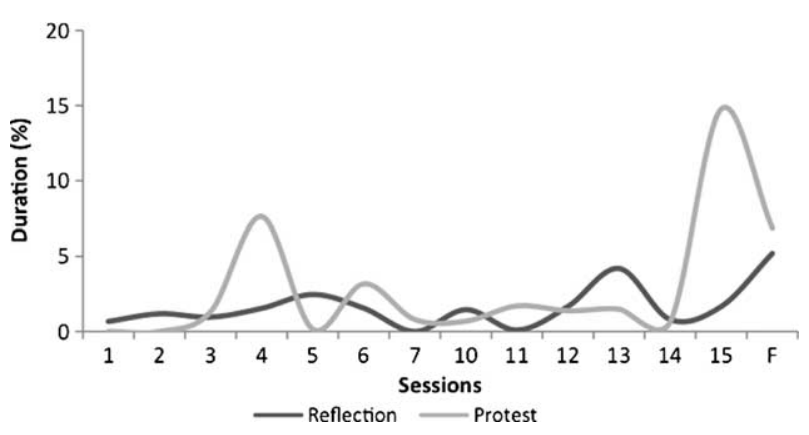

Figure 2. Evolution of reflection and protest i-moments duration (\%) throughout the process. 
Table I. Types of I-moments and examples from the Innovative Moments Coding System: version 1 (Gonçalves, Matos, \& Santos, 2006).

Types of i-moments Examples

Action i-moments:

Specific actions or behaviours that defy the problem.

Reflection i-moments:

Thinking processes that indicate the understanding of something new that makes the problem unacceptable (e.g. thoughts, intentions, interrogations, doubts)

\section{Protest i-moments:}

Resistance, defiance or protest that can be planned or concretised behaviours, thoughts, or/and feelings.

Re-conceptualization i-moments:

Process description, at a meta-cognitive level (the client not only manifests thoughts and behaviours out of the problem dominated story, but also understands the processes that are involved in it)

Performing change i-moments:

References to new projects, activities or investments planned or underway, as a consequence of change.
- New coping behaviours facing obstacles;

- Effective resolution of unsolved problems;

- Active exploration of solutions;

- Restoring autonomy;

- Searching for information about the problem.

- New problem formulations and/or re-formulation of its effects;

- Reconsidering problems causes (e.g. severity, intensity, intentionality, aetiology);

- Consideration of life dilemmas;

- Considering cognitive and affective dilemmas;

- Reflecting about cultural, social and religious demands;

- References of self worth (e.g. strength to fight, positive thinking, positive feelings, well-being references ...);

- Self instructions (e.g. 'you have to fight');

- Reflecting about the intention to fight problems demands (e.g. shame).

- Defiance position toward the problem and problems allies;

- Assertive attitudes towards others;

- Public repositioning towards culturally dominant values.

- References to new/emergent identity versions;

- Re-evaluation of relationships;

- Re-evaluation of experiences within problem development frame (e.g. aetiology, interference, costs ...).

- Generalisation into the future and other life dimensions of therapeutic gains;

- Problematic experience as a resource to new situations;

- Investment in new projects and personal image in private and public spaces;

- Investment in new relationships.
Therapist: What are the aims of the wave for your life? Client: I don't know what the answer is ... the aim of not protecting myself, not to face anything, not to have any dreams ...

I-moments were then considered for every moment or episode that was an exception to this problematic narrative.

\section{I-moments emergence and mutual in-feeding}

Reflection i-moments were present since the first sessions. This first illustration shows how Maria was willing to change, despite the presence of the 'wave's voice'.

\section{First session}

Therapist: You said that 'partly' there's a voice that says there's no use making any effort because you will never get anywhere [Problematic narrative]. But is there another voice? [Opening to new meanings]
Client: Yes, there's another part that seems that I can do everything! [Reflection i-moment] But suddenly, it falls down! Like a castle of cards that we build and then suddenly falls apart! [Return to the problematic narrative]

When Maria stated 'she would never get anywhere' she gave voice to the problematic narrative. The employment of the words never and anywhere shows how definite and determinist this rule had been in her life. She also said that this was 'partly' true, leading the therapist to question the possibility of the emergence of another voice. So, the therapist invited the client to enact a new position through the question 'But is there another voice?' elaborating on possible new meanings outside the problematic narrative. This resulted in the elaboration of a new meaning through an i-moment ('seems that I can do everything').

However, after narrating the i-moment, the word but indicated the re-emergence of the previous and 
opposite voice by saying But suddenly, it falls down! Like a castle of cards that we build and then suddenly falls apart!' By doing so, Maria prevented the i-moment from being amplified and reinforced like the voice of the previous problematic narrative. She used a symbolic helper (see Josephs \& Valsiner, 1998), a castle of cards, in order to express that the i-moment's meaning was not structured enough and it could easily be destroyed.

The previous example involved a mutual infeeding situation, as the i-moment and its potential meaning development was immediately bypassed, returning to the problematic voice.

Maria also started narrating episodes of protest since the early sessions; specifically she defied her husband's power position and the problematic voice in new ways. In the following excerpt, Maria said she wanted to end with the 'wave' completely.

\section{Fourth session}

Therapist: What do you want to do to this 'wave' (externalised label for depressive symptoms)? Today you've defied it ... [Opening to new meanings]

Client: End with it completely, [Protest i-moment] but it seems very difficult to me ... [Return to the problematic narrative]

Therapist: End with it ...! You're ambitious!

One of the goals of narrative therapy was to change the client's relationship with the problem to a more viable one. As the therapist identified an i-moment and opened the conversation to new possible meanings, Maria stated the wish of eliminating the problem in absolute terms like 'completely'. This magical or non realistic objective was immediately counterpointed by her with the difficulty of this task, allowing the problematic narrative to take over the i-moment once again. The gap between her wish and her competence to achieve that task was perceived as so high that she returned to the position of the problematic narrative.

A further example of the dominance of the problematic narrative in Maria's life, and her difficulty in elaborating on the meaning of i-moments is illustrated by the following excerpt.

\section{Ninth session}

Therapist: If the wave was so big and oppressive, you would have never come to our sessions! [Problematic narrative] And you haven't missed one session!
[Opening to new meanings]

Client: No, I didn't. On the way here, to the clinic, I kept thinking 'I'm not going', but then 'no, I'm going!'. I was fighting on the way here ... [Protest i-moment] But I can't fight all the time .... It's very complex ... [Return to the problematic narrative]

The therapist presented the 'wave' as being 'oppressive' but, even so, she stressed that Maria had not missed any of the sessions (highlighting new meanings outside the problematic narrative). This actually could be a window of opportunity for the development of new i-moments of self empowerment as in good outcome cases. Maria narrated a protest i-moment, in which she showed how she defied the problem as she was walking to the clinic, establishing a dialogue with it. However, this voice was not fully elaborated but rather restrained as she emphasised that she could not perform these exceptions 'all the time', returning to the problematic narrative.

In the final sessions, Maria actually decided that she would not leave home, as she was considering initially, mainly because she could not take her oldest son to the shelter with her. Reflection i-moments had an increasing duration as the process progressed and were focused mainly on considerations about self capacity to achieve change. Curiously enough, this content was the exact opposite of what she defined as the 'wave', which was the idea that whatever the efforts she would engage in, she would never achieve positive results and that she was not worthy.

\section{Twelfth session}

Therapist: Definitely, I think these moments are victories towards the wave. If the wave had a total influence on you, you probably would have stopped coming (to therapy) some time ago ...

Client: Yes, the wave tried to dominate me, many times. When I was coming here, to the sessions, I considered ... going back, giving up ... [Problematic narrative]

Therapist: What prevented you from doing it? [Opening to new meanings]

Client: If I told you that there are moments that I thought 'I will say to the therapist: let's move forward (going to the shelter), it doesn't matter, let's not think of anything else, and don't look back' [Reflection i-moment] but later suddenly, immediately, it's finished. The point was erased. I can't do it, I can't decide myself really: I am very 
puzzled about all this ... [Return to the problematic narrative]

The therapist elaborated on the idea that attending the sessions were exceptional moments as Maria defied the 'wave', despite its influence (going back, giving $u p$ ). As she asked what prevented her from obeying the 'wave', opening the discussion to the dialogue between new possible meanings, Maria narrated a reflection i-moment, stating her wish to change expressed through the idea of 'I will' and self instructions. However, this i-moment was again instantly counterpointed by the problematic narrative by stating 'I can't'. This prevented further i-moment elaboration through the help of some kind of symbolism ('The point was erased') disregarding the i-moment's meaning. Maria regulated this opposition by taking over the provocative meaning of the i-moment and its possible potential of being amplified.

In final sessions, data suggested a movement not only toward diversity of i-moments, but a slight change in their quality. A glimpse of empowerment in protest i-moments and new self versions in reflection i-moments could be seen in the next excerpt. These subtypes of i-moments were usually present in successful therapy, but emerging since early phases (Santos \& Gonçalves, 2009).

\section{Last session}

Therapist: Does it happen only with your husband, or with other people?

Client: With other people too. It happens with my mother-in-law. If I have to say I won't do it, I'm not going, if she asks something that I don't want to do, I don't do it. I feel that I don't fear her or my husband anymore. I'm capable of saying 'I'm not doing it and I'm not going'. [Protest i-moment] I've been thinking a lot ... I've forgiven a lot until now ... I've never had respect for myself, and it's time to have respect for myself. [Reflection i-moment]

This process might have meant that some transformations occurred within i-moments, as new meanings seemed to be achieved out of the vicious cycle of mutual in-feeding. These voices suffered some proliferation, showing dynamism. However, they did not evolve into a new narrative of the self, as it seems to happen in good outcome cases.

\section{Discussion}

One of the first conclusions that can be drawn upon in Maria's case was that, despite being a poor outcome case (i.e. continuing violence and severe symptoms), she was able to narrate i-moments and elaborate them in therapeutic conversation. These changes seemed to occur in a context of dynamism. Valsiner (2002) proposed 'if the number of parts in a multivoiced self-system is conceptually allowed to increase [...], the self-system is dynamic, but not developmental' (p. 260). In fact, findings suggested that the system of meanings remained stable, as reflection and protest i-moments enacted did not give place to the narrative elaboration (through an increasing duration) and to the emergence of re-conceptualization and performing change i-moments. The model of therapeutic failure predicted this and was congruent with previously presented theoretical assumptions (see Gonçalves et al., 2009).

Data from this case study suggested that the relations between the problematic narrative and i-moments were regulated in a way that originated the mutual in-feeding processes, sustained along the therapeutic process. The meanings expressed by i-moments were frequently trivialised, neglected or simply taken over by the immediate emergence of the problematic narrative's meanings. So, dialogical relations of opposition and rivalry between the problem's voice and the i-moment were 'solved' by an immediate return to the problem, allowing its perpetuation. This restricted any further elaboration and new meaning complexes did not emerge. This process ended up strengthening the problematic narrative's meanings, maintaining its dominance not only because it was still present, but because it prevented other possible voices from developing. This was actually a dynamic and also a dialogical process, although promoting a stable cyclical movement of returning to the problem along therapy (see Figure 3).

(A)

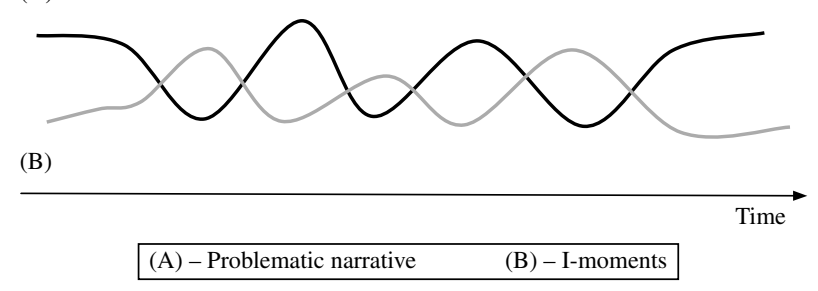

Figure 3. Mutual in-feeding along the therapeutic process. Adapted from Gonçalves, Matos, et al. (2010). 
Another path for development would be that the i-moments could lead to the development of other meanings, or other i-moments, of different types, that would be, in their nature, differentiated from the problematic narrative meanings, as it occurred in the last example provided (see results section). In good outcome cases this occurs through the emergence of re-conceptualization, involving the integration of the previous voices into new meanings. This would be narratively elaborated through an increased duration, and could lead to a sense of authorship of the new narrative.

As process continued, it seemed that Maria's possible self positions were constantly reduced to the one of the problem, as 'one position or voice is admitted as the only possible position' (Gonçalves \& Guilfoyle, 2006, p. 253). The therapist frequently tried to open the conversation to dialogicality, in the sense that she invited Maria to take new positions in her victim discourse through the elaboration of i-moments. This recurrent effort can be, ultimately, argued as becoming, at some point, a part of the oscillatory cycle between the i-moments and the problem. The therapist's proposal seemed to be often accepted, but also soon refused by the client, as part of the return to the problem, maintaining this way the status quo.

\section{Limitations}

In this article the therapeutic stability was explored mainly as a process of mutual in-feeding which could be, in fact, a common process involved in therapeutic failure, although more research is needed on this hypothesis. Other possible explanations for Maria's poor therapeutic outcome can be addressed. It can be associated with the severe depressive symptoms from which she suffered at the beginning of therapy that actually increased to a clinical level at the follow-up. This could indicate that more therapeutic sessions were needed to prevent relapse. Other specific conditions prevented Maria from leaving home and going to a temporary shelter for victims.

On the one hand, it was impossible to take her oldest son with her, according to the shelter's rules. On the other hand, she was not able to cope with her feelings of pity towards her husband. Of course, her history of being abused by her father could be another reason to keep her in this abusive relationship and could also contribute to the maintenance of the severe depressive symptoms. Above all, isolation and lack of social support throughout the marriage led to a reduced net of social relationships, which could have been very helpful in the decision making of going to the shelter. Maria could benefit from a possible inclusion in a therapeutic group of women victims of intimate violence (cf. Dimmitt \& Davilla, 1995, Tutty, Bidgood, \& Rothery, 1993) supplemented with individual therapy. However, this group approach was not available at the time, neither in the institution, nor at others nearby.

If these extrinsic conditions that made therapy more challenging to the client were successfully addressed, and therapeutic change did occur, one can hypothesise that it would be visible through more extensive elaboration of i-moments, breaking the oscillatory movement in which Maria seemed to be entrapped.

This study has the obvious limitation of relying on one poor outcome case. It is not within our knowledge if the same pattern would occur in other poor outcome cases in narrative therapy, or in other treatment approach. It also seems interesting to find out if successful therapeutic cases can, at any stage, present mutual in-feeding situations and how the dynamic stability evolves toward development. One hypothesis is that this change could happen through re-conceptualization, but there is no data to confirm it until now.

\section{Conclusions and implications for practice}

The dialectical exploration and analysis of the processes involved in therapy meaning stability seems to be of interest to researchers and practitioners. It opens the possibility to study the dialogical interchange with appropriate semiotic tools, allowing the analysis of the change processes as it happens in the flow of therapeutic conversation (Santos \& Gonçalves, 2009).

For practitioners, it seems likely that they will recognise the mutual in-feeding process at some point in their clinical practice. Therefore, it seems very important to fully explain the mechanisms involved which prevent change. So, therapists can get familiar with specific markers of stability (such as the return to the problem) and the process of mutual in-feeding. For instance, the maintenance of these markers in middle therapy stages could indicate a possible poor outcome. More importantly, it may give clinicians the tools to not only identify these processes, but to act upon them, inviting clients to position themselves in new ways, and resolving the impasse. Therapists can also adjust or plan their intervention in order to 
promote the narration of other i-moments' types throughout therapy. I-moments could be, in this sense, employed as process measures, giving a global picture of the unfolding change process.

\section{Acknowledgements}

This article was supported by the Portuguese Foundation for Science and Technology (FCT), by the Grant PTDC/PSI/72846/2006 (Narrative Processes in Psychotherapy, 2007-2010) and by the PhD Grant SFRH/BD/16995/2004.

\section{Notes}

1. Cf. Santos \& Gonçalves, 2009, for the dialectic perspective of Josephs and colleagues (Josephs \& Valsiner, 1998; Josephs, Valsiner \& Surgan, 1999) applied to i-moments.

2. See Gonçalves, Matos, and Santos (2009) for an explanation about this preference.

3. In the light of the dialogical self theory, self is understood as having several possible voices. So, identity is composed of different positions (cf. Hermans \& Kempen, 1993) or voices (cf. Stiles, 1997) simultaneously.

\section{References}

Canavarro, M.C.S. (1999). Inventário de sintomas psicopatológicos - B. S. I. In M. R. Simões, M. M. Gonçalves, \& L. S. Almeida (Eds), Testes e provas psicológicas em Portugal [Tests and psychological instruments in Portugal], Vol. II (p. 95-109). Braga: APPORT/SHO.

Davies, B., \& Harré, R. (1990). Positioning: the discursive production of selves. Fournal for the Theory of Social Behavior, 20, 43-63.

Derogatis, L.R. (1982). Self-report measures of stress. In L. Goldberger \& S. Brenznitz (Eds.), Handbook of stress: Theoretical and clinical aspects (pp. 270-290). New York: Free Press.

Dimmitt, J., \& Davilla, Y.R. (1995). Group psychotherapy for abused women: A survivor-group prototype. Applied Nursing Research, 8 (1), 3-7.

Gedo, P.M. (1999). Single case studies in psychotherapy research. Psychoanalytic Psychology, 16, 274-280.

Gonçalves, M.M., \& Guilfoyle, M. (2006). Dialogism and psychotherapy: Therapists' and clients' beliefs supporting monologism. Fournal of Constructivist Psychology, 19, 251-271.

Gonçalves, M.M., Matos, M., \& Santos, A. (2006). Sistema de Codificação dos Momentos de Inovação: Versão 1 [IMCS-Innovative Moments Coding System: Version 1]. Braga: University of Minho: Available from the authors.

Gonçalves, M.M., Matos, M., \& Santos, A. (2009). Narrative therapy and the nature of "innovative moments" in the construction of change. Fournal of Constructivist Psychology, 22, 1-23.

Gonçalves, M.M., Mendes, I., Ribeiro, A., Angus, L., \& Greenberg, L. (in press). Innovative moments and change in emotional focused therapy: The case of Lisa. Fournal of Constructivist Psychology.
Gonçalves, M., Matos, M., Salgado, J., Santos, A., Mendes, I., Ribeiro, A., Cunha, C., \& Gonçalves, J. (2010). Innovations in psychotherapy: Tracking the narrative construction of change. In J. D. Raskin, S. K. Bridges, \& R. Neimeyer (Eds.), Studies in meaning 4: constructivist perspectives on theory, practice, and social justice. New York: Pace University Press.

Gonçalves, M.M., Ribeiro, A., Matos, M., Santos, A., \& Mendes, I. (2009). The Innovative Moments Coding System: A coding procedure for tracking changes in psychotherapy. In S. Salvatore, J. Valsiner, S. Strout, \& J. Clegg (Eds.), YIS: Yearbook of Idiographic Science 2009-Volume 2. Rome: Firera Publishing Group.

Hermans, J.M.H., \& Kempen, H.J.G. (1993). The dialogical self: Meaning as movement. San Diego, CA: Academic Press.

Hilliard, R.B. (1993). Single-case methodology in psychotherapy process and outcome research. Fournal of Consulting and Clinical Psychology, 61, 373-380.

Josephs, I., \& Valsiner, J. (1998). How does autodialogue work? Miracles of meaning maintenance and circumvention strategies. Social Psychology Quarterly, 61, 68-83.

Josephs, I., Valsiner, J. , \& Surgan, S.E. (1999). The process of meaning construction - dissecting the flow of semiotic activity. In J. Brandstadter \& R. M. Lerner (Eds), Action and development. theory and research through the life span (pp. 257-282). London: Sage Publications.

Kazdin, A.E. (1981). Drawing valid inferences from case studies. fournal of Consulting and Clinical Psychology, 49, 183-192.

Kiesler, D.J. (1981). Empirical clinical psychology: Myth or reality? fournal of Consulting and Clinical Psychology, 49, 121-215.

Machado, C., \& Matos, M. (2001). A intervenção narrativa com um grupo de mulheres maltratadas: Da desconstrução da posição de vítima à reconstrução de identidades preferenciais. In M. Gonçalves \& O. Gonçalves (Eds.), Psicoterapia, discurso e narrativa: A construçao conversacional da mudança (pp. 207-234). Coimbra: Quarteto Editora.

Matos, M. (2006). Violência nas relações de intimidade. Estudo sobre a mudança psicoterapêutica da mulher [Violence in intimate relationships: A research about the psychotherapeutic change in women]. University of Minho: Unpublished doctoral dissertation.

Matos, M., \& Gonçalves, M. (2002). Espaços identitários na vitimação conjugal: Da narrativa problemática à narrativa preferencial [Identity spaces in intimate violence: From the problematic narrative to the preferred narrative]. Psychologica, 29, 53-70.

Matos, M., Santos, A., Gonçalves, M.M., \& Martins, C. (2009). Innovative moments and change in narrative therapy. Psychotherapy Research, 19, 68-80.

Molenaar, P.C.M., \& Valsiner, J. (2005). How generalization works through the single case: A simple idiographic process analysis of an individual psychotherapy. International fournal of Idiographic Science, Article 1. Retrieved 6 January, 2006, from http://www.valsiner.com/articles/molenvals.htm.

Morgan, D.L., \& Morgan, R.K. (2001). Single-participant research design - bringing science to managed care. American Psychologist, 56, 119-127.

Ribeiro, A., Gonçalves, M., \& Ribeiro, E. (2009). Processos narrativos de mudança em psicoterapia: Estudo de um caso de sucesso de terapia construtivista [Narrative change processes 
in psychotherapy: A good-outcome case of narrative therapy]. Psychologica, 50, 181-203.

Santos, A., \& Gonçalves, M. (2009). Innovative moments and change processes in psychotherapy: An exercise in new methodology. In J. Valsiner, P. C. M. Molenaar, M. C. D. P. Lyra \& N. Chaudhary (Eds.), Dynamic process methodology in the social and developmental sciences (pp. 493-526). New York: Springer.

Santos, A., Gonçalves, M., Matos, M., \& Salvatore, S. (2009). Innovative moments and change pathways: A successful case of narrative therapy. Psychology and Psychotherapy: Theory, Research and Practice, 82, 449-466.

Sarbin, T.R. (1986). The narrative and the root metaphor for psychology. In T. R. Sarbin (Ed.), Narrative psychology: The storied nature of human conduct (pp. 3-21). New York: Praeger.

Stiles, W.B. (1997). Signs and voices: Joining conversation in progress. British fournal of Medical Psychology, 70, 169-176.

Stiles, W.B. (2003). When is a case study scientific research? Psychological Bulletin, 38, 6-11.

Stiles, W.B. (2007). Theory-building case studies of counselling and psychotherapy. Counselling and Psychotherapy Research, 7, 122-127.

Tutty, L.M., Bidgood, B.A., \& Rothery, M.A. (1993). Support groups for battered women: Research on their efficacy. Fournal of Family Violence, 8, 325-343.

Valsiner, J. (2002). Forms of dialogical relations and semiotic autoregulation within the self. Theory and Psychology, 12, 251-265.

White, M., \& Epston, D. (1990). Narrative means to therapeutic ends. New York: Norton.

White, M. (2007). Maps of narrative practice. New York: Norton.

Winslade, J.M. (2005). Utilizing discursive positioning in counseling. British fournal of Guidance $\mathcal{E}$ Counselling, 3, 351-364.
Yin, R.K. (2005). Estudo de caso: Planejamento e métodos. Porto Alegre: Bookman.

\section{Biographies}

Anita Santos, $\mathrm{PhD}$, currently teaches research methods in psychology at ISMAI - Instituto Superior da Maia (Maia, Portugal). Her research interests are related to psychotherapeutic process research, within the theoretical framework of narrative therapy and self dialogical theory. She is co-author of several papers in this area, namely case studies and microanalysis of psychotherapeutic processes.

Miguel M. Gonçalves, $\mathrm{PhD}$, is associate professor at the Department of Psychology, University of Minho (Braga, Portugal). He is interested in narrative studies of the self and in narrative psychotherapy. $\mathrm{He}$ is presently developing a research project on the role that narrative innovations play in the promotion of psychotherapeutic change.

Marlene Matos, $\mathrm{PhD}$, is an assistant professor in the School of Psychology at the University of Minho, and also a psychotherapist. She has peer-reviewed publications in the areas of psychotherapy, victimology and forensic psychology. She has ongoing research support for the studies 'Stalking in Portugal: Prevalence, impact and intervention' and 'Abused women: A support group research'. 